OPEN ACCESS

Edited by:

Xianlong Wang,

Baylor College of Medicine,

United States

Reviewed by:

Harald Pothmann

University of Veterinary Medicine

Vienna, Austria

Nazli Akin,

Vrije University Brussel, Belgium

Satoshi Sugimura,

Tokyo University of Agriculture and

Technology, Japan

*Correspondence:

Mehdi Azari

mehdiazari@shirazu.ac.ir orcid.org/0000-0001-5730-9891

TORCID:

Mojtaba Kafi

orcid.org/0000-0002-7215-483X

Specialty section: This article was submitted to Animal Reproduction -

Theriogenology,

a section of the journal

Frontiers in Veterinary Science

Received: 20 February 2021

Accepted: 22 March 2021

Published: 23 April 2021

Citation:

Kafi M, Ghaemi M, Azari M, Mirzaei A,

Azarkaman S and Torfi Y (2021) Effects

of Pre-ovulatory Follicular Fluid of

Repeat Breeder Dairy Cows on Bovine

Fertility Transcriptomic Markers and

Oocytes Maturation and Fertilization

Capacity. Front. Vet. Sci. 8:670121

doi: 10.3389/fvets.2021.670121

\section{Effects of Pre-ovulatory Follicular Fluid of Repeat Breeder Dairy Cows on Bovine Fertility Transcriptomic Markers and Oocytes Maturation and Fertilization Capacity}

\author{
Mojtaba Kafi ${ }^{1+}$, Mehran Ghaemi ${ }^{2}$, Mehdi Azari ${ }^{1 *}$, Abdolah Mirzaei ${ }^{1}$, Samad Azarkaman ${ }^{1}$ \\ and Yusof Torfi ${ }^{1}$
}

${ }^{1}$ Department of Clinical Sciences, School of Veterinary Medicine, Shiraz University, Shiraz, Iran, ${ }^{2}$ Department of

Pathobiology, School of Veterinary Medicine, Shiraz University, Shiraz, Iran

The current study aimed to determine the effects of the preovulatory follicular fluid (FF) of normal heifer $(\mathrm{NH})$ and repeat breeder cows with subclinical endometritis (SCE) or without (nSCE) on oocyte maturation (Experiment 1) and fertilization rates (Experiment 2). Moreover, the pattern of gene expression of cumulus oocyte-complexes was evaluated in Experiment 1. In Experiment 1, nuclear maturation in the nSCE group was higher, compared to that in the SCE group $(P=0.05)$. In addition, the oocyte nuclear maturation in the normal heifer was significantly higher, in comparison to that of SCE groups $(P<$ 0.05). Furthermore, the mean percentage of normal oocyte fertilization was higher in the nSCE group, compared to that in the SCE group $(P<0.05)$. The expressions of growth differentiation factor, GDF9; steroidogenic acute regulatory, StAR and follicle-stimulating hormone receptor, $F S H r$ in the $\mathrm{NH}$ group were significantly higher, compared to those in SCE and nSCE groups $(P<0.05)$. Moreover, the expressions of all genes in the nSCE group were not significant, in comparison to those in the SCE group $(P>0.05)$. The supplementation of oocyte maturation medium with FF from pre-ovulatory follicles of repeat breeder cows resulted in less oocyte maturation and cumulus cell expansion. In conclusion, the lower fertility in RB cows could be ascribed to the lower oocyte maturation rate and less expression of GDF9, StAR, and FSHr in the cumulus-oocyte complexes.

Keywords: endometritis, follicular fluid, gene expression, lipopolysaccharide, repeat breeder cow

\section{INTRODUCTION}

Repeat breeder (RB) cows are described as subfertile cows that do not become pregnant at least after three consecutive services. Different factors, including uterine infections, hormonal imbalances, mismanagement in the artificial insemination, nutritional factors, and genetic disorders may result in the occurrence of RB syndrome in dairy cows (1). A related study reported subclinical endometritis (SCE) in $52.7 \%$ of RB cows (2). In addition, researchers denoted that SCE is a major risk factor for reproductive failure resulting in lower reproductively of dairy cows $(3,4)$. On the contrary, it was found that SCE is not the cause of RB syndrome in dairy cows (5). 
Follicular fluid (FF) provides an ideal microenvironment for the growth and development of the ovulatory follicle and the oocyte. Poor FF quality in ovulatory follicles has been frequently linked to low pregnancy rates in lactating cows. Metabolic dysfunctions and uterine infections are two main causes of low FF quality in ovulatory follicles (6-8). Furthermore, it was observed that the addition of ovulatory FF of RB Holstein heifers to oocyte maturation media disturbs oocyte maturation (9). The examination of the pre-ovulatory FF proteome showed differences in protein contents of less fertile cows, compared to those of more fertile ones (10). In addition, another study demonstrated that changes in FF composition in cows with liver problems lead to an impairment in the nuclear maturation of oocytes and the development of blastocyst (11).

Communication between the oocyte and its surrounding cumulus cells is an important event for development of a competent oocyte (12). Growth differentiation factor (GDF9) and steroidogenic acute regulatory $(S t A R)$ proteins play a major role in oocyte developmental competence $(13,14)$. In addition, the expression of follicle-stimulating hormone receptor (FSHr) has an important role in the cumulus cells expansion and the final maturation of COCs (15). Oocyte development, follicular growth, and estrous cyclicity were adversely affected in lactating cows with infections of the uterus or mammary gland (16, 17). Furthermore, it was reported that even though the clinical signs of uterine infection were disappeared, reduced fertility may persist in the infected cows for a variable length of time (18). Lipopolysaccharide (LPS) which is a major part of the outer leaflet of Gram-negative bacteria is emanated from the bacterial infections of the uterus and transported to the FF of ovulatory follicles. The higher levels of LPS in FF were associated with lower fertility in cows $(19,20)$. In a study, experimentally induced mastitis by Escherichia coli decreased the quality of pre-ovulatory FF, which this in turn, resulted in reduced oocyte developmental competence (21). Moreover, Shimizu et al. (22) indicated that uterine LPS may contribute to ovarian cyst development in cows. Moreover, the FF collected from preovulatory follicles of cows with mastitis and endometritis was showed to contain LPS $(20,21)$. Very recently, it was observed that the FF LPS concentration of pre-ovulatory follicles in cows with SCE was significantly higher, compared to that of cows without SCE (23). No data is available on the effects of FF obtained from the preovulatory follicle of RB dairy cows with SCE on oocyte maturation and fertilization. With this background in mind, the current study aimed to assess the effects of FF obtained from the preovulatory follicle of $\mathrm{RB}$ cows with SCE on oocyte maturation, fertilization, and the expression of genes related to fertility in cultured cumulus-oocyte complexes (COCs).

\section{MATERIALS AND METHODS}

\section{Experiment 1}

\section{Animals}

The present study was approved by the Ethical and Research Committee of Veterinary Faculty, Shiraz University (97GCU1M1251), Iran. RB cows entered the study from a commercial Holstein dairy farm in Alborz, Iran $\left(35^{\circ} 82^{\prime} \mathrm{N}\right.$, $\left.50^{\circ} 97^{\prime} \mathrm{E}\right)$. Free-stall barns were used for the maintaining of cows and mixed feed staffs containing $40 \%$ fodder (corn silage and alfalfa) and $60 \%$ concentrated meal (soybean meal, corn, wheat bran, barley, trace minerals, and vitamins) were fed. The examination of the reproductive system of RB cows did not show any reproductive clinical signs. Means \pm SD of parity, milking days, and the artificial insemination number of repeat breeder cows entered to this study were $3.3 \pm 1.7,277.9 \pm 82.8$, and $5.2 \pm 1.6$, respectively. Virgin heifers $(n=5)$ in good body condition score and 14-15 months aged were also selected as control. All heifers became pregnant in the next estrous cycle after sampling. This group of normal virgin heifers was used as the control due the presence of the maximum elements of fertility in the FF in the preovulatory follicles of these animals. The experimental design of the present study is shown in Figure 1.

\section{Diagnosis of Subclinical Endometritis and Follicular Fluid Sampling}

All the procedures including the diagnosis of subclinically endometriotic cows, ovulation synchronization protocol, follicular fluid sampling were conducted as described in a study by Heidari et al. (23). In brief, the estrus time of the heifers and cows were synchronized using either a two injection of PGF $2 \alpha$ (500 $\mu$ g Cloprostenol sodium, Estroplan Parnel Living Science) with 11 days interval in heifers or an Ovsynch program in RB cows. Using a cytobrush (Heinz Herenz, Hamburg, Germany), uterine secretions were collected from RB cows. For cytology, the uterine samples were spread on a slide, immersed $1 \mathrm{~min}$ in $90 \%$ alcohol for fixation and stained with Giemsa. RB cows with more than cut-off point of $\geq 3 \%$ PMNs were categorized into RBs with SCE $(n=10)(2,24)$ and those with $<3 \%$ PMNs were considered as RBs without subclinical endometritis (nSCE, $n=13$ ). Six to twelve hours after detecting standing estrus in synchronized animals, transrectal ultrasonography was performed to confirm the presence of the preovulatory follicle $14-17 \mathrm{~mm}$ in diameter (SIUI CTS-900 Ultrasound, Shantou Institute of Ultrasonic Instruments Co., Ltd., China). The FF was aspirated as described previously by Kafi et al. (9). Briefly FF was aspirated trans-rectally using a long fine-needle covered by a hard plastic tube under the caudal epidural anesthesia. Uterine cytology showed out of 23 RB cows, 10 (43.5\%) cases exhibited cytological signs of SCE whereas 13 (56.5\%) cows did not.

\section{LPS Assay of FF}

The amount of LPS in the FF of pre-ovulatory follicles of each group was measured using an ELISA Kit (Hangzhou East biopharm CO., LTD, China). The intra-assay coefficient of variation (intra assay $\mathrm{CV}$ ) and the inter-assay $\mathrm{CV}$ was obtained at $<10$ and $<12 \%$, respectively. Assay range and assay sensitivity were reported as $10-3000 \mathrm{EU} / \mathrm{ml}$ and $3.8 \mathrm{EU} / \mathrm{ml}$, respectively. The Follicular fluid used in the present study was basically the same as what we used in our previous study (23). The LPS concentration in pooled FF of the preovulatory follicles of 


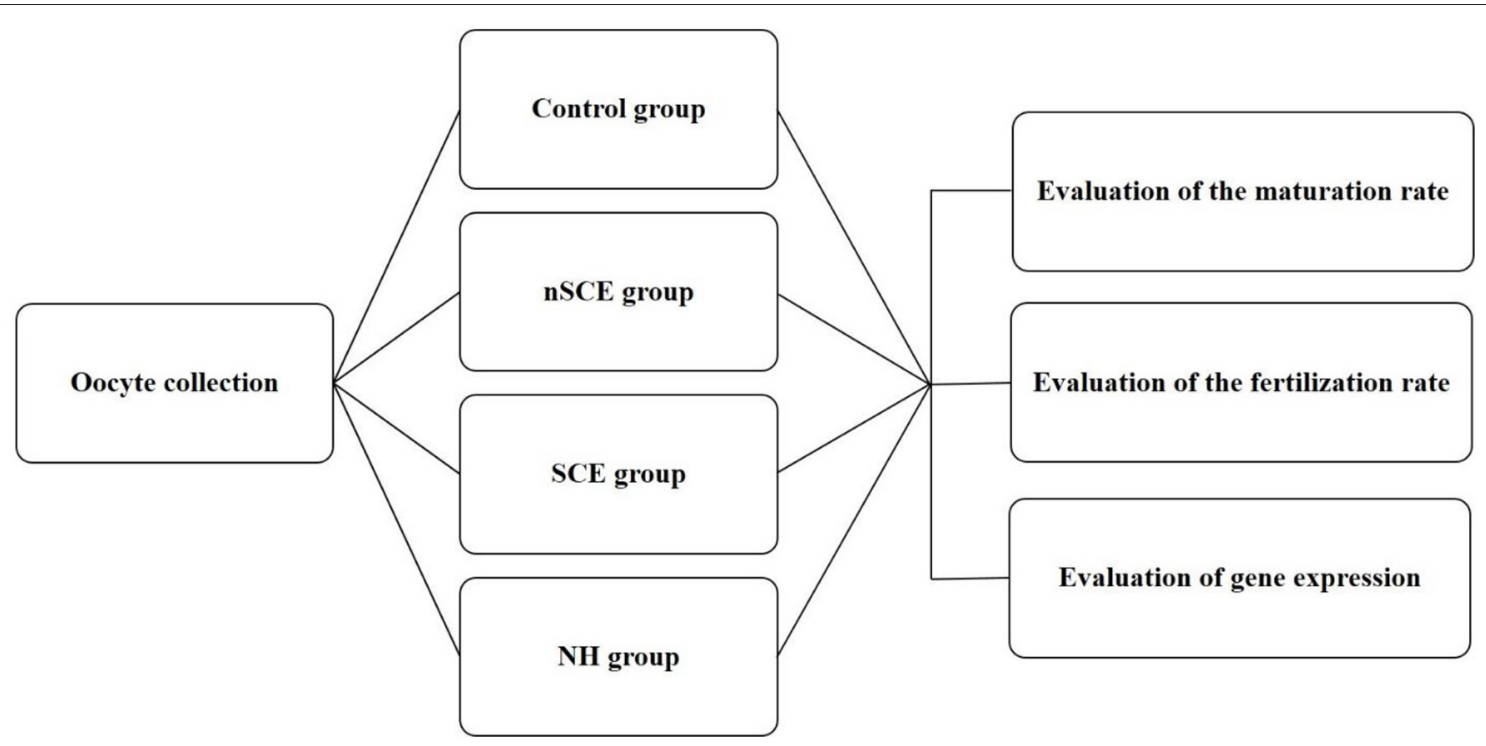

FIGURE 1 | Experimental design. Control: COCs were cultured in TCM-199 medium supplemented with 10\% FCS, 5 IU/mL hCG, $10 \mathrm{ng} / \mathrm{ml}$ EGF and 0.1 IU/ml human FSH for $24 \mathrm{~h}$; nSCE: COCs were cultured in the TCM-199 medium supplemented with 10\% filtered FF of the nSCE for $24 \mathrm{~h}$; SCE: COCs were cultured in the TCM-199 medium supplemented with 10\% filtered FF of the SCE for $24 \mathrm{~h}$; NH: COCs were cultured in the TCM-199 medium supplemented with $10 \%$ filtered FF of the $\mathrm{NH}$ for $24 \mathrm{~h}$.

animals in NH, nSCE, and SCE groups was 410, 862, and 1063 $\mathrm{EU} / \mathrm{ml}$, respectively.

\section{In vitro Maturation of Oocytes}

The FF collected from five RB cows with a greater percentage of PMNs (SCE; PMNs $\geq 3 \%, n=5$ ), and the FF from five RB cows with a less percentage of PMNs (nSCE; PMNs $<3 \%, n=$ 5 ) and, in addition, the FF of five normal heifers $(\mathrm{NH}, n=5)$ were pooled separately to be substitute with serum supplement in the oocyte maturation media. Fetal calf serum (FCS) was used for serum supplement in the control group of in vitro maturation in Experiment 1.

For oocyte collection, the ovaries of slaughtered cows were collected and transferred to the laboratory within $2 \mathrm{~h}$ at $32-35^{\circ} \mathrm{C}$ in phosphate-buffered saline (PBS). The ovaries were washed in sterile $\mathrm{PBS}\left(37^{\circ} \mathrm{C}\right)$ for three times; thereafter, the cumulusoocyte complexes (COCs) were aspirated with a 20 G hypodermic needle attached to a $10 \mathrm{ml}$ disposable syringe. COCs with more than three layers of cumulus cells and a finely granulated homogenous ooplasm were selected and entered the in vitro maturation (25). Medium HEPES- buffered TCM-199 (Sigma, USA) supplemented with $10 \%$ FCS was used for washings of the selected COCs. In total, 735 good quality COCs were assigned to four groups. In technical control group, COCs $(n=204)$ were cultured in TCM-199 medium supplemented with 10\% FCS, 5 IU/mL hCG (Karma, Germany), 10 ng/ml EGF (Sigma, USA), and $0.1 \mathrm{IU} / \mathrm{ml}$ human FSH (Follitrope, South Korea). On the other hand, in the NH group, COCs $(n=141)$ were cultured in the TCM-199 medium supplemented with 10\% filtered FF of the normal heifer. In addition, in the nSCE group, COCs $(n=$ 217) were cultured in TCM-199 medium supplemented with $10 \%$ filtered FF of nSCE cows. Also, in the SCE group, COCs $(n=173)$ were matured in the TCM-199 medium supplemented with $10 \%$ filtered FF of SCE cows. All cultures were carried out in four wellculture dishes (NuncTM, Denmark). In all maturation media, $50 \mu \mathrm{g} / \mathrm{ml}$ Gentamicin (Sigma, USA) was also added. Groups of $30-50$ COCs were cultured for $24 \mathrm{~h}$ in a $500 \mu \mathrm{l}$ culture media at $38.5^{\circ} \mathrm{C}$ in $5 \% \mathrm{CO}_{2}$.

\section{Evaluation of Nuclear Maturation of Oocytes}

After $24 \mathrm{~h}$, the COCs were evaluated for nuclear maturation using the aceto-orcein staining method. Cumulus expansion degree was also graded using a stereo microscope from 0 (no expansion), 1 (partial expansion) to 2 (complete expansion). Also, for the evaluation of nuclear maturation of the oocytes, matured COCs were pipetted frequently to denude the oocytes which were then fixed using acetic alcohol under coverslips for $24 \mathrm{~h}$. The oocytes were then stained using $1 \%$ aceto-orcein. Oocytes which did not reach to the metaphase were classified as "immature," oocytes that chromosomes arranged in metaphase plate and peripherally located in the ooplasm were classified as 'metaphase I (MI), oocytes with a polar body and the metaphase II plate were classified as "mature" and oocytes showed chromosomal abnormality categorized at "abnormals."

\section{RNA Extraction}

RNA was extracted from 50 COCs of each group using the RNeasy micro RNA extraction kit (Qiagen, Germany) as instructed by the manufacturer. In each group, four independent replicates were performed for extraction. Then, extracted RNA of 
all samples was quantified by Nanodrop spectrometer in order to adjust the amount of starting material in the next step.

\section{Real-Time Polymerase Chain Reaction}

After oocyte maturation in $24 \mathrm{~h}$, the expression levels of GDF9, StAR, and FSHr in COCs of NH, SCE, and nSCE groups were determined using real-time RT-PCR. For relative quantification, $G A P D H$ housekeeping gene was used as the normalizer gene, and the $\mathrm{NH}$ group was assumed as the calibrator group.

\section{cDNA Synthesis}

Five hundred nanogram of each extracted RNA was entered to cDNA synthesis. REVERT-L RT kit (AmpliSens biotechnologies, Korea) was used to synthesize cDNA from extracted RNA according to the manufacturer's instruction. One No-RT control for each group was included in cDNA synthesis by the omitting of reverse transcriptase enzyme from cDNA synthesis. No-RT control is a control for DNA digestion in RNA extraction step and it must be negative in the Real-time PCR test to ensure that positive results were not due to genomic DNA remnants.

\section{Real Time PCR}

Firstly, the efficacy of each real-time PCR test was assessed by running the test on a cDNA serial dilution. If a real-time PCR had an efficiency lower than $95 \%$ or higher than $105 \%$, the test was optimized to improve its efficiency. Power SYBR Green PCR Master Mix (Thermo Fisher Scientific, US) was consumed for the real-time PCR tests using a Corbett 6000 instrument (Qiagen, Germany). Twenty microliter of the total volume of each PCR master mix consisted of $10 \mu \mathrm{l}$ of Power master mix, $1 \mu \mathrm{l}$ of each primer $(5 \mu \mathrm{M}), 1 \mu \mathrm{l}$ of cDNA, and $7 \mu \mathrm{l}$ of Distilled water. The initial denaturation step was performed at the beginning of real-time PCR for $10 \mathrm{~min}$ at $95^{\circ} \mathrm{C}$, followed by 40 cycles of $15 \mathrm{~s}$ at $95^{\circ} \mathrm{C}, 30 \mathrm{~s}$ at annealing temperature (Table $\mathbf{1}$ ), and $30 \mathrm{~s}$ at $72^{\circ} \mathrm{C}$. The results were analyzed using the $\Delta \Delta \mathrm{Ct}$ method and the expression level of each gene in different groups was calculated in relation to the calibrator group (normal heifer).

\section{Experiment 2} In vitro Fertilization

In vitro oocyte maturation was carried out in four groups as described in Experiment 1. After in vitro maturation of the oocytes, groups of 35-50 COCs were transferred into four wellculture dishes containing $500 \mu \mathrm{l}$ Tyrode's medium as fertilization medium. Frozen semen which previously tested in the laboratory for IVF was used for fertilization. Motile spermatozoa from frozen/thawed semen were obtained using the swim-up method and were then added to wells containing oocytes at a final concentration of $10^{6}$ spermatozoa ml-1 (12). Oocytes and spermatozoa were co-incubated at $38.5^{\circ} \mathrm{C}$ for $18 \mathrm{~h}$ in $5 \% \mathrm{CO}_{2}$.

\section{Assessment of the Fertilization Rate}

After the fertilization period, surrounding cumulus cells of presumptive zygotes were removed by repeated pipetting which was mounted on glass slides under coverslips fixed in an acetic alcohol solution for at least $24 \mathrm{~h}$ and then were stained using $1 \%$ aceto-orcein. Presumptive zygotes with two pronuclei were classified as "fertilized," while the presumptive zygotes without pronuclear formation, absent of sperm in the ooplasm, and without second polar body were classified as "nonfertilized," presumptive zygotes with more than two pronuclei were classified as "polyspermy," and oocytes with other nuclear structures were classified as "abnormal fertilization."

\section{Statistical Analysis}

The obtained data were analyzed in SPSS software (version 23). The Shapiro-Wilk test was used to assess the normality of the distribution of data sets. Differences in the cumulus expansion, maturation and fertilization rates among groups were statistically analyzed using an ANOVA test (Post Hoc LSD). Moreover, One Way ANOVA was applied for the statistical analysis of Real-time RT-PCR results. A $p<0.05$ was considered statistically significant. Experiments 1 and 2 were performed in five independent replicates.

\section{RESULTS}

\section{Experiment 1}

\section{Percentage of Cumulus Expansion and Oocyte Nuclear Maturation}

The mean $( \pm \mathrm{SD})$ percentage of COCs demonstrated that fully expanded cumulus cells were significantly lower in SCE group than the control, nSCE and $\mathrm{NH}$ groups $(30.4 \pm 8.3$ vs. 65.7 $\pm 12.1,46.0 \pm 12.9$, and $48.8 \pm 11.9$, respectively; $P<0.05$ ). Furthermore, the percentage of fully expanded cumulus cells between nSCE and NH was not significantly different $(P>0.05)$. The mean $( \pm \mathrm{SD})$ percentage of nuclear maturation (M II stage) of the SCE, nSCE, NH, and control groups is shown in Table 2. The percentage of oocyte nuclear maturation in the control group was significantly higher compared to that in other groups $(P<$ $0.05)$. Further, the mean $( \pm S D)$ percentage of nuclear maturation in the nSCE group was higher than that of the SCE group (69.4 \pm 10.6 vs. $61.1 \pm 8.0 ; P=0.05$ ). Also, the percentage of oocyte nuclear maturation in the $\mathrm{NH}$ group was significantly higher than that in the SCE group $(72.9 \pm 4.9$ vs. $61.1 \pm 8.03 ; P<0.05)$.

\section{Real Time RT-PCR}

The mRNA expression of GDF9, StAR, and FSHr in the NH group was significantly higher than those of SCE and nSCE groups $(P<0.05)$. The mRNA expressions of GDF9, StAR, and FSHr in nSCE in comparison to those of SCE were not significantly different $(P>0.05)$. The results in detail are presented in Figure 2.

\section{Experiment 2}

The results in detail are presented in Table 3. The mean $( \pm S D)$ percentage of normal oocyte fertilization was higher in the nSCE than the SCE group $(58.0 \pm 9.8$ vs. $40.2 \pm 4.5 ; P<0.05)$. Furthermore, the mean $( \pm S D)$ percentage of normal oocyte fertilization in the nSCE group, in comparison with the NH group was not significant (58.0 \pm 9.8 vs. $48.1 \pm 10.7 ; P>0.05)$. 
TABLE 1 | Primers used for real time RT PCR of different genes.

\begin{tabular}{|c|c|c|c|}
\hline Gene & Primer sequences $\left(5^{\prime}\right.$ to $\left.3^{\prime}\right)$ & Annealing temperature $\left({ }^{\circ} \mathrm{C}\right)$ & Accession number \\
\hline GDF9 & $\begin{array}{l}\text { For: TGAAGATATGATAGCCACTAAG } \\
\text { Rev: CTCCTCCTTACACAACAC }\end{array}$ & 58 & NM_174681.2 \\
\hline $\mathrm{FSHr}$ & $\begin{array}{l}\text { For: GAATGATGTCTTGGAAGTGATAG } \\
\text { Rev: CGATGTATAGCAGGTTGTTG }\end{array}$ & 58 & NM_174061.1 \\
\hline StAR & $\begin{array}{l}\text { For: TGCCGAAGACCATCATCAAC } \\
\text { Rev: GAGCCCTCAAACCCATTCAG }\end{array}$ & 62 & NC_037330.1 \\
\hline GAPDH & $\begin{array}{l}\text { For: ATCTCGCTCCTGGAAGATG } \\
\text { Rev: TCGGAGTGAACGGATTCG }\end{array}$ & 60 & NM_001034034 \\
\hline
\end{tabular}

Primer sequences, annealing temperatures, and accession numbers. All primers designed in this study using Beacon Designer (Primier Biosoft) software.

TABLE 2 | Mean ( \pm SD) percentages of normally mature oocytes following addition of follicular fluid collected from cows with no subclinical endometritis (nSCE), subclinical endometritis (SCE) and normal heifer $(\mathrm{NH})$ to the maturation media.

\begin{tabular}{|c|c|c|c|c|c|}
\hline Group name & Number & MII oocytes, $n$ (\%) & Immature oocytes, $n$ (\%) & MI oocytes, $n$ (\%) & Degraded oocytes, $n(\%)$ \\
\hline Control & 204 & $177(86.7 \pm 1.9)^{\mathrm{a}}$ & $8(3.7 \pm 3.7)$ & $15(7.8 \pm 3.3)^{a}$ & $4(1.7 \pm 2.9)$ \\
\hline nSCE & 217 & $149(69.4 \pm 10.6)^{b}$ & $24(9.5 \pm 12.8)$ & $41(19.6 \pm 7.3)^{\mathrm{b}}$ & $3(1.3 \pm 2.4)$ \\
\hline SCE & 173 & $105(61.1 \pm 8.0)^{\mathrm{c}}$ & $24(12.7 \pm 16.8)$ & $39(22.9 \pm 13.8)^{b}$ & $5(3.1 \pm 5.0)$ \\
\hline $\mathrm{NH}$ & 141 & $103(72.9 \pm 4.9)^{\mathrm{bd}}$ & $2(1.06 \pm 2.6)$ & $33(24.2 \pm 6)^{b}$ & $3(1.7 \pm 2.8)$ \\
\hline
\end{tabular}

In control group, oocytes are cultured with FCS.

Different letters within a column showed statistically significant difference $(P \leq 0.05)$.

MII (metaphase II), MI (metaphase I).

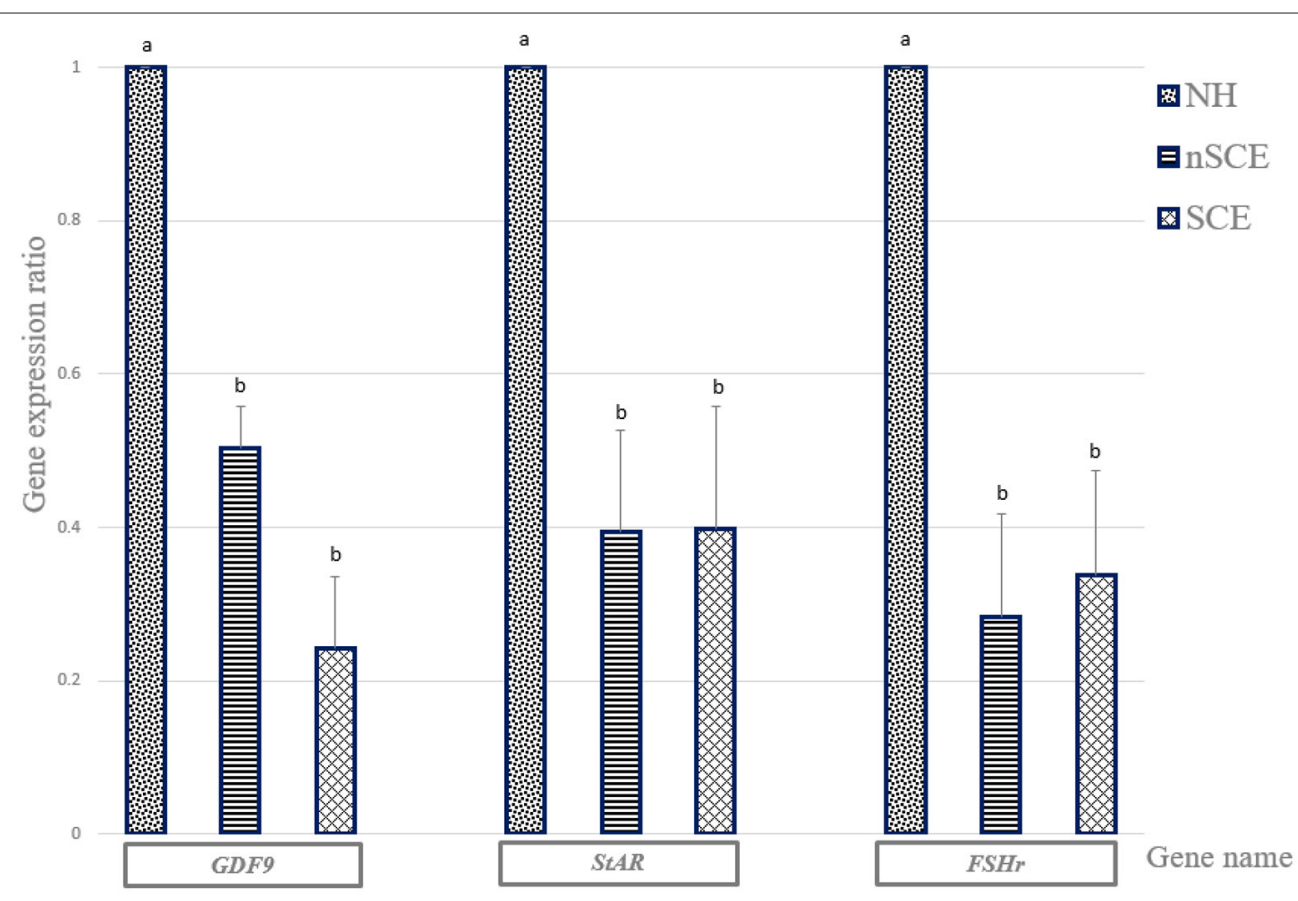

FIGURE 2 | The expression ratio of GDF9, StAR, and FSHr genes. Bar charts (with standard errors) shows the expression ratio of genes in COCs cultured in the media containing pre-ovulatory FF of normal heifer $(\mathrm{NH})$ and cows with subclinical endometritis (SCE), and without subclinical endometritis ( $\mathrm{nSCE}$ ). In each gene, different letters indicates statistically significant difference $(P<0.05)$. 
TABLE 3 | Mean ( \pm SD) percentages of normally fertilized oocytes following addition of follicular fluid collected from cows with no subclinical endometritis (nSCE), subclinical endometritis (SCE) and normal heifer $(\mathrm{NH})$ to the maturation media.

\begin{tabular}{|c|c|c|c|c|c|}
\hline Group name & Number & Fertilization, $\boldsymbol{n}(\%)$ & Non fertilized, $\boldsymbol{n}$ (\%) & Polyspermy, $n$ (\%) & Abnormal fertilization, $n(\%)$ \\
\hline Control & 132 & $85(66.1 \pm 12.8)^{\mathrm{a}}$ & $39(26.5 \pm 17.5)^{\mathrm{a}}$ & $3(2.6 \pm 2.8)$ & $5(4.5 \pm 5.5)$ \\
\hline nSCE & 161 & $94(58.0 \pm 9.8)^{\mathrm{ab}}$ & $63(39.6 \pm 8.1)^{\mathrm{ab}}$ & $10(0.5 \pm 1.2)$ & $3(1.7 \pm 3.2)$ \\
\hline SCE & 173 & $70(40.2 \pm 4.5)^{\mathrm{c}}$ & $100(57.8 \pm 5.5)^{\mathrm{C}}$ & - & $3(1.8 \pm 2.1)$ \\
\hline $\mathrm{NH}$ & 120 & $58(48.1 \pm 10.7)^{\mathrm{bc}}$ & $54(44.9 \pm 9.8)^{b c}$ & $1(0.8 \pm 1.9)$ & $7(5.9 \pm 6.9)$ \\
\hline
\end{tabular}

Different letters within a column showed statistically significant difference $(P<0.05)$.

\section{DISCUSSION}

The present study strived to apply an in vitro model that could simulate an intra-follicular condition which occurs in the final stages of oocyte maturation in the pre-ovulatory follicles of $\mathrm{RB}$ cows and animals with the highest level of fertility, virgin heifers. Using FF as a component of oocyte maturation media has previously been used as a model to examine the oocyte competence in either mastitic or healthy cows (21). The results of experiment 1 showed that cumulus expansion and nuclear maturation of oocytes decreased when they were cultured in vitro using $\mathrm{FF}$ of pre-ovulatory follicles of $\mathrm{RB}$ cows with SCE, compared to nSCE and NH groups. The lower nuclear maturation rate in the SCE group could be due to the fact that the LPS level in the FF of pre-ovulatory follicles in RB cows with SCE was higher than that of the other groups in the present study. Similarly, Magata and Shimizu (26) using a dose-response approach found a deleterious effect of LPS on in vitro oocyte development in cattle. Zhao et al. (27) further showed that the LPS disrupted meiotic spindle structure and induced oxidative stress in bovine oocytes resulting in low nuclear maturation. The lower nuclear maturation rate in the SCE group in the present study explains the results of our previous study in which a lower blastocyst yield was observed when the bovine oocytes matured in vitro using FF of pre-ovulatory follicles of RB cows with SCE (23). One more significant finding in the present study (Experiment 2) was the lower percentage of normally in vitro fertilized oocytes observed in the SCE group compared to the nSCE group. The proper fertilization fundamentally depends on normal nuclear maturation and cumulus expansion to perform numerous functions required for fertilization support $(28,29)$.

In Experiment 1, the expression levels of GDF9, StAR, and $\mathrm{FSHr}$ mRNA in COCs were determined using RT-PCR. Recent researches have shown that GDF9 protein plays a major role in oocyte developmental competence $(13,30)$, follicular growth, and luteinization in mammals (31). The higher oocyte nuclear maturation rates in the $\mathrm{NH}$ than the SCE group can be explained by the fact the GDF9 expression level in the matured COCs in the $\mathrm{NH}$ group was significantly higher than those of the SCE groups in the present study. Although the nuclear maturation rate was higher in the nSCE group than that of the SCE group, however, no difference was observed in the expression level of GDF9 in the matured COCs between the nSCE and SCE groups.
StAR mRNA expression in the COCs was significantly reduced in both nSCE and SCE groups in comparison with that of the $\mathrm{NH}$ group. This could be ascribed to the higher levels of LPS in the pre-ovulatory follicles of repeat breeder cows comparing to that of the virgin heifers. Steroidogenic acute regulatory protein is encoded by the StAR mRNA. StAR in COCs has been reported to be involved in the developmental competence of the oocyte and the embryo in bovine (32), and sheep (14). Magata et al. (33) found that a greater amount of LPS in the FF disrupted the function of theca and granulosa cells in the follicle leading to less steroid production. Also, SCE (34), and particularly LPS (35), can cause inflammation in bovine granulosa cells, which disrupts Steroidogenesis in follicles. Similarly, we observed a significant lower nuclear maturation rates in SCE groups than those of the $\mathrm{NH}$ group. The higher LPS level in the FF of the preovulatory follicles in the $\mathrm{RB}$ cows in the present study could be responsible for the lower expression of StAR mRNA in the matured COCs in the nSCE and SCE groups in the present study. Also, our result was in agreement with those of Campos et al. (36), Herzog et al. (37), Shimizu et al. (22), and Magata et al. (33). They observed that LPS reduced the StAR mRNA expression which could result in the reduction of steroid production. Our recent study (23) and others (20, 38) showed a lower concentration of $17-\beta$ estradiol associated with a high LPS in the FF of the pre-ovulatory follicles of SCE cows.

FSH has an important role in the cumulus cells expansion and the final maturation of COCs in cows and other mammals (15). The results of the present study showed a significant reduction in FSHr mRNA expression of the matured COCs in SCE group in comparison with that of the NH group. This could be explained by the presence of higher amount of LPS in FF of the preovulatory follicles in SCE group. Although the LPS concentration was higher in the FF of preovulatory follicles of the RB cows with SCE than that of the nSCE cows in the present study, however, the pattern of expression of GDF9, StAR, and FSHr in the in vitro matured COCs did not explain the observed differences in the maturation and fertilization rates between the nSCE and SCE groups. Although it is difficult to explain this finding, however we assume that the effect on GDF9, StAR, and FSHr expression is associated with clinical endometritis rather than the sub-clinical endometritis. Alternatively, the bacterial type $\left(\mathrm{G}^{+}\right.$and $\left.\mathrm{G}^{-}\right)$may have influenced the mRNA expression of our candidate genes as shown by Asaf et al. (21). It is important to note that significantly higher level of the expression of GDF9, StAR, and FSHr in the 
matured COCs of the $\mathrm{NH}$ group as compared to those of the $\mathrm{RB}$ groups suggest the presence of a disturbance in the normal function and expression of the genes involved in the fertility in $\mathrm{RB}$ cows. The cumulus cells surrounding the immature oocyte play a critical role in the development of the oocyte. Expansion of the cumulus cells is one of the first morphological predictive criteria of the successful completion of oocyte maturation (29). In addition, results of different researches have shown that gene expression patterns in the cumulus cells are an acceptable marker for oocyte quality $(39,40)$. Results of the present study showed that the mean percentage of fully expanded cumulus cells were significantly lower in SCE group than the other experimental groups. This can explain the lower nuclear oocyte maturation and fertilization rates in the SCE group comparing with that of the nSCE group in the preset study.

\section{CONCLUSIONS}

In conclusion, the low oocyte maturation and fertilization rates could explain the disturbed fertility in RB cows specifically with subclinical endometritis. This implies the presence of poor quality of microenvironment for the final stages of oocyte development in the pre-ovulatory follicle of RB cows. Additionally, the lower fertility in RB cows could be ascribed to the lower oocyte developmental competence and less expression of GDF9, StAR, and FSHr in the cumulus-oocyte complexes.

\section{REFERENCES}

1. Perez-Marin CC, Molina Moreno L, Vizuete CG. Clinical approach to the repeat breeder cow syndrome. In: A Bird's-Eye View of Veterinary Medicine, 1st, Edn. London: IntechOpen Press (2012). p. 337-362. doi: 10.5772/ 31374

2. Salasel B, Mokhtari A, Taktaz T. Prevalence, risk factors for and impact of subclinical endometritis in repeat breeder dairy cows. Theriogenology. (2010) 74:1271-8. doi: 10.1016/j.theriogenology.2010.05.033

3. Gilbert RO. The effects of endometritis on the establishment of pregnancy in cattle. Reprod Fertil Dev. (2011) 24:252-7. doi: 10.1071/RD11915

4. López-Helguera I, López-Gatius F, Garcia-Ispierto I. The influence of genital tract status in postpartum period on the subsequent reproductive performance in high producing dairy cows. Theriogenology. (2012) 77:133442. doi: 10.1016/j.theriogenology.2011.10.038

5. Pothmann, H., Prunner, I., Wagener, K., Jaureguiberry, M., de la Sota, R.L., Erber, R., et al. The prevalence of subclinical endometritis and intrauterine infections in repeat breeder cows. Theriogenology. (2015) 83:1249-53. doi: 10.1016/j.theriogenology.2015.01.013

6. Leroy J, Van Soom A, Opsomer G, Goovaerts I, Bols P. Reduced fertility in high yielding dairy cows: are the oocyte and embryo in danger? Part II mechanisms linking nutrition and reduced oocyte and embryo quality in high yielding dairy cows. Reprod Domest Anim. (2008) 43:623-32. doi: 10.1111/j.1439-0531.2007.00961.x

7. Williams EJ, Fischer DP, Noakes DE, England GCW, Rycroft A, Dobson H, et al. The relationship between uterine pathogen growth density and ovarian function in the postpartum dairy cow. Theriogenology. (2007) 68:549-59. doi: 10.1016/j.theriogenology.2007.04.056

8. Cheong SH, Filho OJ, Absalon-Medina VA, Schneider A, Butler WA, Gilbert RO. Uterine and systemic inflammation influences ovarian follicular function in postpartum dairy cows. PLoS ONE. (2017) 12:e0177356. doi: 10.1371/journal.pone.0177356

\section{DATA AVAILABILITY STATEMENT}

The data that support the findings of this study are available from the corresponding author upon reasonable request.

\section{ETHICS STATEMENT}

The animal study was reviewed and approved by Ethical and Research Committee of Veterinary Faculty, Shiraz University (97GCU1M1251).

\section{AUTHOR CONTRIBUTIONS}

MK designed this study and involved in the lab works and writing this paper. MG performed Real time RT-PCR and contributed to writing paper. MA performed the laboratory work and revised the manuscript. AM performed the follicular fluid collection. SA and YT, DVM students, were involved in the laboratory work.

\section{ACKNOWLEDGMENTS}

The authors thank the farm staff at the Mallard dairy farm, Alborz, for their kind cooperation. They are also grateful to Dr. Mehdi Heidari for their technical help to follicular fluid collection. This study was financially supported by grant No. 97GCU2M1251 of the Shiraz University and the Center of Excellence for Research on High-Producing Dairy Cows.

9. Kafi M, Azari M, Chashnigir O, Gharibzadeh S, Aghabozorgi Z, Asaadi A, et al. Inherent inferior quality of follicular fluid in repeat breeder heifers as evidenced by low rates of in vitro production of bovine embryos. Theriogenology. (2017) 102:29-34. doi: 10.1016/j.theriogenology.2017.07.011

10. Zachut M, Sood P, Levin Y, Moallem U. Proteomic analysis of preovulatory follicular fluid reveals differentially abundant proteins in less fertile dairy cows. J Proteom. (2016) 139:122-9. doi: 10.1016/j.jprot.2016.03.027

11. Tanaka H, Shibano K, Monji Y, Kuwayama T, Iwata H. Liver condition affects bovine oocyte qualities by changing the characteristics of follicular fluid and plasma. Reprod Domest Anim. (2013) 48:619-26. doi: 10.1111/rda. 12135

12. Azari M, Kafi M, Ebrahimi B, Fatehi R, Jamalzadeh M. Oocyte maturation, embryo development and gene expression following two different methods of bovine cumulus-oocyte complexes vitrification. Vet Res Commun. (2017) 41:49-56. doi: 10.1007/s11259-016-9671-8

13. Ferreira RM, Chiaratti MR, Macabelli CH, Rodrigues CA, Ferraz ML, Watanabe YF, et al. The infertility of repeat-breeder cows during summer is associated with decreased mitochondrial DNA and increased expression of mitochondrial and apoptotic genes in oocytes. Biol Reprod. (2016) 94:66-71. doi: 10.1095/biolreprod.115.133017

14. Valiollahpoor Amiri M, Deldar H, Ansari Pirsaraei Z. Impact of supplementary royal jelly on in vitro maturation of sheep oocytes: genes involved in apoptosis and embryonic development. Syst Biol Reprod Med. (2016) 62:31-8. doi: 10.3109/19396368.2015.1088102

15. Ongaratto FL, Andrés V Cedeño AV, Rodriguez-Villamil P, Tríbulo A, Bó G A. Effect of FSH treatment on cumulus oocyte complex recovery by ovum pick up and in vitro embryo production in beef donor cows. Anim Reprod Sci. (2020) 214:106274. doi: 10.1016/j.anireprosci.2020.106274

16. Sheldon IM, Noakes DE, Rycroft AN, Pfeiffer DU, Dobson H. Influence of uterine bacterial contamination after parturition on ovarian dominant follicle selection and follicle growth and function in cattle. Reproduction. (2002) 123:837-45. doi: 10.1530/rep.0.1230837 
17. Lavon Y, Leitner G, Moallem U, Klipper E, Voet H, Jacoby S, et al. Immediate and carryover effects of Gram-negative and Gram- positive toxin-induced mastitis on follicular function in dairy cows. Theriogenology. (2011) 76:94253. doi: 10.1016/j.theriogenology.2011.05.001

18. Bromfield JJ, Santos JEP, Block J, Williams RS, Sheldon IM. Physiology and endocrinology symposium: uterine infection: linking infection and innate immunity with infertility in the high-producing dairy cow. J Anim Sci. (2015) 93:2021-33. doi: 10.2527/jas.2014-8496

19. Mateus L, Lopes da Costa L, Diniz P, Ziecik AJ. Relationship between endotoxin and prostaglandin (PGE2 and PGFM) concentrations and ovarian function in dairy cows with puerperal endometritis. Anim Reprod Sci. (2003) 76:143-54. doi: 10.1016/S0378-4320(02)00248-8

20. Herath S, Williams EJ, Lilly ST, Gilbert RO, Dobson H, Bryant CE, et al. Ovarian follicular cells have innate immune capabilities that modulate their endocrine function. Reproduction. (2007) 134:683-93. doi: 10.1530/REP-07-0229

21. Asaf S, Leitner G, Furman O, Lavon Y, Kalo D, Wolfenson D, et al. Effects of Escherichia coli-and Staphylococcus aureus-induced mastitis in lactating cows on oocyte developmental competence. Reproduction. (2014) 147:33-43. doi: 10.1530/REP-13-0383

22. Shimizu T, Ishizawa S, Magata F, Kobayashi M, Fricke P, Miyamoto A. Involvement of lipopolysaccharide in ovarian cystic follicles in dairy cow: expressions of LPS receptors and steroidogenesis-related genes in follicular cells of cystic follicles. Anim Reprod Sci. (2018) 195:89-95. doi: 10.1016/j.anireprosci.2018.05.010

23. Heidari M, Kafi M, Mirzaei A, Asaadi A, Mokhtari A. Effects of follicular fluid of preovulatory follicles of repeat breeder dairy cows with subclinical endometritis on oocyte developmental competence. Anim Reprod Sci. (2019) 205:62-9. doi: 10.1016/j.anireprosci.2019.04.004

24. Pascottini OB, Hostens M, Sys P, Vercauteren P, Opsomer G. Cytological endometritis at artificial insemination in dairy cows: prevalence and effect on pregnancy outcome. J Dairy Sci. (2017) 100:588-97. doi: $10.3168 /$ jds.2016-11529

25. Lorenzo PL, Illera MJ, Illera JC, Illera M. Enhancement of cumulus expansion and nuclear maturation during bovine oocyte maturation in vitro by the addition of epidermal growth factor and insulin-like growth factor I. Reproduction. (1994) 101:697-701. doi: 10.1530/jrf.0.1010697

26. Magata F, Shimizu T. Effect of lipopolysaccharide on developmental competence of oocytes. Reprod Toxicol. (2017) 71:1-7. doi: 10.1016/j.reprotox.2017.04.001

27. Zhao SJ, Pang YW, Zhao XM, Du WH, Hao HS, Zhu HB. Effects of lipopolysaccharide on maturation of bovine oocyte in vitro and its possible mechanisms. Oncotarget. (2017) 8:4656-67. doi: 10.18632/oncotarget.13965

28. Dey SR, Deb GK, Ha AN, Lee JI, Bang JI, Lee K.L. Coculturing denuded oocytes during the in vitro maturation of bovine cumulus oocyte complexes exerts a synergistic effect on embryo development. Theriogenology. (2012) 77:e1077. doi: 10.1016/j.theriogenology.2011.10.009

29. Lonergan P, Fair T. Maturation of oocytes in vitro. Annu Rev Anim Biosci. (2016) 4:255-68. doi: 10.1146/annurev-animal-022114-110822

30. Regassa A, Rings F, Hoelker M. Transcriptome dynamics and molecular crosstalk between bovine oocyte and its companion cumulus cells. BMC Genomics. (2011) 12:57. doi: 10.1186/1471-2164-12-57
31. Dalbies-Tran R, Cadoret V, Desmarchais A, Elis S, Maillard V, Monget P, et al. A comparative analysis of oocyte development in mammals. Cells. (2020) 9:1002. doi: 10.3390/cells9041002

32. Salhab M, Papillier P, Perreau C, Guyader-Joly C, Dupont J, Mermillod P, et al. Thymosins $\beta-4$ and $\beta-10$ are expressed in bovine ovarian follicles and upregulated in cumulus cells during meiotic maturation. Reprod Fertil Dev. (2010) 22:1206-21. doi: 10.1071/RD10015

33. Magata F, Horiuchi M, Echizenya R, Miura R, Chiba S, Matsui M, et al. Lipopolysaccharide in ovarian follicular fluid influences the steroid production in large follicles of dairy cows. Anim Reprod Sci. (2014) 144:6-13. doi: 10.1016/j.anireprosci.2013.11.005

34. Green M, Ledgard A, Beaumont S, Berg M, McNatty K, Peterson A, et al. Long-term alteration of follicular steroid concentrations in relation to subclinical endometritis in postpartum dairy cows. J Anim Sci. (2011) 89:3551-60. doi: 10.2527/jas.2011-3958

35. Bromfield JJ, Sheldon IM. Lipopolysaccharide initiates inflammation in bovine granulosa cells via the TLR4 pathway and perturbs oocyte meiotic progression in vitro. Endocrinology. (2011) 152:5029-40. doi: 10.1210/en.2011-1124

36. Campos FT, Rincon JAA, Acosta DAV. The acute effect of intravenous lipopolysaccharide injection on serum and intrafollicular HDL components and gene expression in granulosa cells of the bovine dominant follicle. Theriogenology. (2017) 89:244-9. doi: 10.1016/j.theriogenology.11.013

37. Herzog K, Strüve K, Kastelic JP, Piechotta M, Ulbrich SE, Pfarrer C, et al. Escherichia coli lipopolysaccharide administration transiently suppresses luteal structure and function in diestrous cows. Reproduction. (2012) 144:46776. doi: 10.1530/REP-12-0138

38. Price JC, Bromfield JJ, Sheldon IM. Pathogen-associated molecular patterns initiate inflammation and perturb the endocrine function of bovine granulosa cells from ovarian dominant Follicles via TLR2 and TLR4 pathways. Endocrinology. (2013) 154:3377-86. doi: 10.1210/en.2013-1102

39. Matoba S, Bender K, Fahey AG, Mamo S, Brennan L, Lonergan $P$, et al. Predictive value of bovine follicular components as markers of oocyte developmental potential. Reprod Fertil Dev. (2014) 26:337-45. doi: $10.1071 / \mathrm{RD} 13007$

40. Bunel A, Jorssen EP, Merckx E, Leroy JL, Bols PE, Sirard MA. Individual bovine in vitro embryo production and cumulus cell transcriptomic analysis to distinguish cumulus-oocyte complexes with high or low developmental potential. Theriogenology. (2015) 83:228-37. doi: 10.1016/j.theriogenology.2014.09.019

Conflict of Interest: The authors declare that the research was conducted in the absence of any commercial or financial relationships that could be construed as a potential conflict of interest.

Copyright (C) 2021 Kafi, Ghaemi, Azari, Mirzaei, Azarkaman and Torfi. This is an open-access article distributed under the terms of the Creative Commons Attribution License (CC BY). The use, distribution or reproduction in other forums is permitted, provided the original author(s) and the copyright owner(s) are credited and that the original publication in this journal is cited, in accordance with accepted academic practice. No use, distribution or reproduction is permitted which does not comply with these terms. 